\title{
Weight Management of Young Women with Down Syndrome: C-ICAN Meal Plan
}

\author{
JuliSu DiMucci-Ward, Stephan L. Brown \\ Department of Cell Biology and Physiology, Edward Via College of Osteopathic Medicine, Spartanburg, SC, USA \\ Email: slbrown@vcom.edu
}

How to cite this paper: DiMucci-Ward, J. and Brown, S.L. (2021) Weight Management of Young Women with Down Syndrome: C-ICAN Meal Plan. Case Reports in Clinical Medicine, 10, 393-402.

https://doi.org/10.4236/crcm.2021.1011049

Received: August 18, 2021

Accepted: November 27, 2021

Published: November 30, 2021

Copyright (c) 2021 by author(s) and Scientific Research Publishing Inc. This work is licensed under the Creative Commons Attribution International License (CC BY 4.0).

http://creativecommons.org/licenses/by/4.0/ (c) (i) Open Access

\begin{abstract}
Primary care physicians are in a unique position to provide a holistic and individualized care to their patients with Down Syndrome. These patients share common medical problems with general population; however, they often are medically complex and present with cardiac, orthopedic, and endocrine challenges such as overweight-obesity and related comorbidities that occur with more frequency in this unique population. The prevention of overweight-obesity is an important public health issue for both the general population and for the population of individuals with Down Syndrome. If abnormal weight gain is treated early and effectively many secondary comorbidities can be prevented or ameliorated. This case report discusses the impact of implementing a Consistent Individualized Carbohydrate controlled Anti-inflammatory Nutrition plan (C-ICAN) as part of the treatment plan for a young woman with Down Syndrome (DS). The C-ICAN meal plan is a low glycemic load meal plan with $30 \%$ to $35 \%$ calories from fat, $20 \%$ to $25 \%$ calories from protein, $40 \%$ to $45 \%$ calories from carbohydrate, and goal of $25 \mathrm{gm}$ fiber per day. The C-ICAN meal plan combines the Mediterranean diet because of its well-established anti-inflammatory, and cardiovascular benefits, with a high protein and low glycemic-load meal plan to improve satiety and glycemic control. In this case the patient and her caregivers adjusted to a structured meal pattern well, weight balance resulted, and mealtime stress was reduced.
\end{abstract}

\section{Keywords}

Down Syndrome, Obesity, Weight Management, C-ICAN, Glycemic Load

\section{Background}

The genetic disorder of Down Syndrome (DS), results when there is a third copy 
of chromosome 21 (HSA21). It is a well-recognized clinical condition with distinctive facial features, morphological abnormalities and of intellectual disabilities (ID). DS occurs approximately in 1 in 700 live births. It is one of the most common chromosome abnormalities in humans [1]. Evidence has shown that Down Syndrome patients are likely to have a more obese body habitus than the general population without DS and lean body mass [2] [3] [4]. Front line physicians are in a unique position to provide individualized care to their patients with Down Syndrome and other developmental disabilities across the lifespan. Individuals with Down Syndrome have medical problems common in the general population; however, they some problems such as muscular hypotonia, leukemias, sleep apnea, obesity and associated comorbidities, early dementia, and accelerated aging to name only a few, occur with more frequency in this unique population [5] [6] [7].

Overweight-Obesity are terms used to describe fat storage which is frequently but not always complicated by co-morbidities such as metabolic syndrome, hypertension, diabetes, cardiovascular diseases, cancer, and psychological stress, and contribute to a decreased quality of life [8] [9]. Ominously, the rate of obesity and overweight continues to increase each year in the United States [10]. Obesity and overweight are issues which impact us in two ways, as individuals and at the community level. The Global Burden of Disease study (GBD) in 2016 finds that high BMI, poor diet, and high fasting blood glucose levels are increasing and among the most pressing national public health concerns the United States faces today [11] [12] [13]. It is well established in the literature that obesity and chronic disease costs include large health care expenditures, decrease productivity, disability, and human suffering [14] [15].

Approximately $1 \%$ to $3 \%$ of the United States population are diagnosed with intellectual and developmental disabilities [16]. Research has shown that the prevalence of obesity and overweight is greater among the population individuals with intellectual and disabilities (IDD) than the general population [17]. While there has been a great deal of research regarding obesity in the general population, the literature is sparse in addressing this issue in the segment of the population who have IDD, such as Down Syndrome (DS) [4] [17] [18]. Individuals with DS are noted to have a decrease in total energy requirements likely secondary to decreased lean muscle mass among other yet determined factors3. Individuals with DS generally exhibit lower levels of physical fitness and higher levels of fatness compared to their peers in the general population [19] [20].

Recent NHANES surveys in the USA and found that eating frequency was inversely associated with body weight status [21]. Meal pattern/timing and composition matters for the general population and for individuals with DS and other IDD. Fat although calorically dense it provides satiety and important nutrients to the diet. Protein is also an important component of meals. Substituting protein for simple carbohydrate enhances satiety, diet induced thermogenesis and is associated with improved blood pressure [22]. Furthermore, when in a 
negative calorie balance situation as in a weight loss diet, protein helps preserve lean body mass which minimizes the loss of or resting energy expenditure (REE) [23]. Many different types of diets will enable individuals to lose weight yet keeping the weight off long term is the problem. It has been estimated that only 1 in 6 overweight adults report having maintained a weight loss of approximately $10 \%$ for 1 one year [24]. Evidence is building that following a low glycemic load diet attenuates the fall in resting energy expenditure (REE) that results after weight loss. Additionally, a calorically restricted low glycemic diet has been shown to result in decreased BMI, insulin resistance, percentage body fat, and leptin concentrations [25] [26] [27]. Beyond these macronutrients, when discussing the prevention of obesity and its associated co-morbidities in individuals with DS or even those in the general non-affected population 2 priorities must be kept in mind: first, there must be adequate nutrition, of both macro and micronutrients, to stay in anabolism. Secondly, individuals need to feel secure and have self-determination regarding their food choices as is developmentally appropriate for them if any meal plan is to become a new lifestyle pattern.

The case presented here illustrates the weight and diet challenges commonly faced by young adults with DS. Initially the standard dietary approach was undertaken with initial success that waned over time. The problem of overweight obesity is a complex multidimensional problem generally that is even a bit more complex for an individual with DS. In this case, due to a weight gain pattern, increase physical mobility challenges, and behavior changes the nutrition plan changed and was individualized for this patient and the C-ICAN meal pattern was implemented.

The C-ICAN diet is a consistent individualized carbohydrate anti-inflammatory nutrition plan that provides a structured, moderate fat, low glycemic load meal pattern. This meal plan not only provided better weight management, eliminated hunger, and improved our patient's quality of life it also improved the family mealtime dynamics. The C-ICAN meal pattern may even enable patients with Down Syndrome to be tracked on the growth charts of typically developing children and be compared to the average body mass indices (BMI) of adults in their age range.

\subsection{Data Sources and Methodology Ease of Use}

After IRB approval and permission was obtained from the patient's parents a retrospective case study was undertaken. The patient's medical records were de-identified and collected. Reported histories, nutritional interventions and treatment plans, consultations, and physical findings to include trending BMIs from April of 2009 to January 2017 were reviewed. A literature review was completed using both the VCOM library catalogue and PubMed using keywords to include "Down Syndrome," "nutrition," "obesity," "body mass index," "comorbidities," "medical nutrition therapy," "trisomy 21," "adult," "primary care," and 
"preventative care." Growth charts of normal female patients were obtained from the CDC and growth charts of female Down Syndrome patients without medical nutritional therapy (MNT) were obtained from the Journal de Pediatria4. BMI data for adult female patients with and without Down Syndrome was obtained from the Journal of Intellectual Disability Research 2. Growth chart data and adult BMI data were compared to the growth chart and serial BMIs of the Down Syndrome patient receiving MNT in this case study.

\subsection{Case Presentation}

20-year-old women with Down Syndrome presented in feeding clinic with complaints of abnormal weight gain, GERD, constipation, hypotonia, and history of erosive esophagitis. Recent EGD showed mild gastritis. Caregiver reported recent increase in patient complaining of hunger, resulting in uncontrolled snacking and behavior challenges. Family history of hyperlipidemia and hypertension. Initially patient was prescribed a standard 1500 calorie DASH diet which improved her symptoms for two plus years. However, over time a slow weight gain trend emerged, and lack of satiety became problematic. To provide satiety we individualized her diet by increasing the total fat, protein, and fiber content, and lowered the caloric content to prevent weight gain. The final diet (The C-ICAN meal pattern) consisted of 1200 to 1400 calorie low glycemic load, moderate fat, and high fiber diet was ordered and implemented along with meal patterning. The family and patient were also encouraged to keep an active lifestyle.

\subsection{Case Report Summary}

The patient was referred to the feeding and growth clinic by her primary care physician for gastroesophageal reflux disease (GERD) with abnormal weight gain. Past medical history included Ventricular septal defect (VSD) repair in infancy, hypotonia, dysphagia, aerophagia, constipation, a tonsillectomy and adenoidectomy for sleep apnea, and GERD with erosive esophagitis. The patient's GERD was largely controlled with medications, with minimal discomfort which varied with the meals she consumed. Her initial physical exam revealed Ht. 56.75 inches, weight $115.25 \mathrm{lbs}$. BMI $25.25 \mathrm{~kg} / \mathrm{m}^{2}$. She was followed by a registered dietician and initially placed on a structured diet plan, which included breakfast, lunch, and dinner, with 2 - 3 snacks per day. The diet plan mirrored a 1500 calorie Dietary Approach to Stop Hypertension (DASH) diet, which allows $27 \%$ total calories from fat, $18 \%$ from protein and $55 \%$ from carbohydrates. Her BMI slowly increases up to 29.02 during almost 3 years. It is important to note that patient had increasing joint pain which limited her mobility in the previous year. Overweight-obesity are proinflammatory. During a follow-up visit the mother reported that for the last 4 months the patient was sneaking foods outside of the diet plan and had complaints of hunger.

Due to the increasing BMI and the marked change in the patient's behavior which impacted the patient-family dynamics negatively the nutrition treatment 
plan change. The C-ICAN meal plan was implemented and adjusted to a 1200 1400 calorie, $30 \%$ to $35 \%$ heart healthy fat, 1.3 gm protein $/ \mathrm{kg}$, low glycemic load meal plan. These 3 meals and 3 snack pattern was calculated to have 30 grams of complex carbohydrates per meal and 15 grams per snack, with protein evenly spread throughout her meals and snacks ( 0.6 gm protein/gram carbohydrate). The patient enjoyed low glycemic fruits/vegetables, rich in nutrients and fiber, which benefit both the microbiome and gastrointestinal motility. The meal plan continued to include three meals per day with 3 snacks per day. In addition to the C-ICAN plan the patient and family were encouraged to be physically active 45 to 60 mins daily. The regular structure of the meal plan eased the patient's anxiety, provided satiety, and increased compliance with the diet. The patient's BMI decreased to $25.70 \mathrm{~kg} / \mathrm{m}^{2}$ in approximately 16 months.

Three months later the patient had an elective laparoscopic hysterectomy with salpingectomy, and the caregivers were unable to implement the C-ICAN plan due to family restructuring. On a follow-up visit the patient presented to clinic with a new diagnosis of psoriatic arthritis which was followed by rheumatology. At this visit her BMI was $29.63 \mathrm{~kg} / \mathrm{m}^{2}$. The family situation had stabilized; so, at the C-ICAN was restarted and followed consistently. Importantly the patient and family restarted her previous physical activity routine. Over time, the patient's BMI decreased to $28.50 \mathrm{~kg} / \mathrm{m}^{2}$ in May-2016; and it was expected this trend would continue to her goal BMI of $25 \mathrm{~kg} / \mathrm{m}^{2}$ providing the current nutrition plan was adhered to and dietitian support continued.

\section{Conclusion}

This case illustrates that a Consistent-Individualized Carbohydrate Anti-inflammatory Nutrition plan (C-ICAN) structured, high fiber, moderate fat, high protein, and low glycemic diet, was effective in this patient in managing obesity, preventing weight gain, improved patient's satiety, and decreased caregiver stress. Interestingly the patient's challenges with constipation and reflux also abated.

\section{Results}

A calorie controlled, a structured, high fiber, moderate fat, high protein and low glycemic diet was effective for this patient. When she followed the diet plan closely her BMI decreased to $25.71 \mathrm{~kg} / \mathrm{m}^{2}$. At a BMI of $25.71 \mathrm{~kg} / \mathrm{m}^{2}$ she was in the 25th percentile for a Down Syndrome female without MNT (Figure 1) and below the 85th percentile for a 20 -year-old on a standard female growth chart (Figure 2). Furthermore, throughout the ages of 20 - 27 years, her BMI consistently remained lower than that of same-aged females with Down Syndrome and was only slightly higher than the BMIs of same-aged females without Down Syndrome (Figure 3). Even when facing barriers to physical activity and an increased propensity to gain fat mass after her hysterectomy, the patient's BMI was maintained around $28 \mathrm{~kg} / \mathrm{m}^{2}$. 


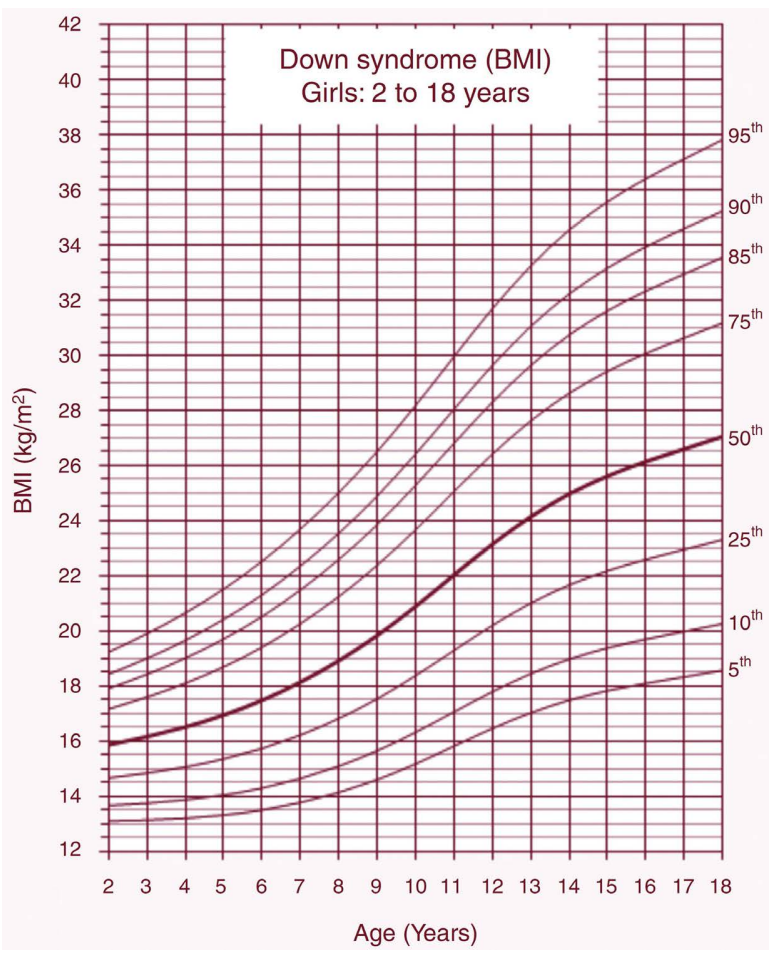

Figure 1. Growth chart of a patient with Down Syndrome without MNT. The patient's BMI at age 20 was 25.945 , which falls in the 50th percentile for an 18-year-old on this growth chart.

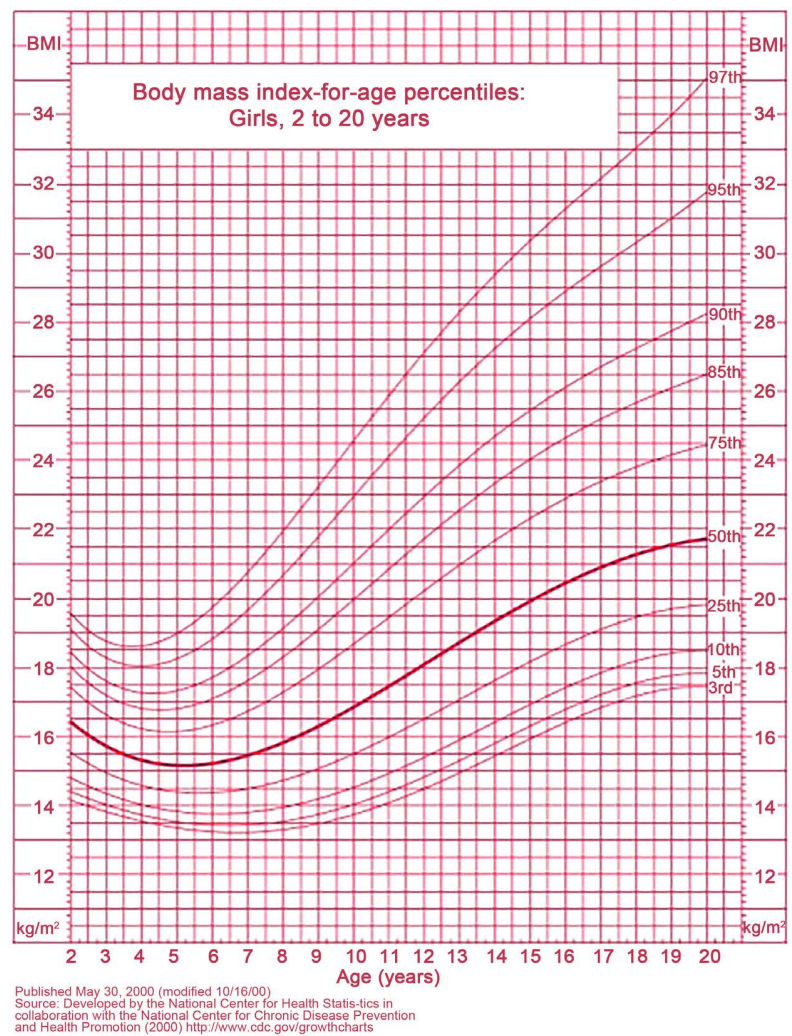

Figure 2. Growth chart of an average developing female. The patient's BMI at age 20 was 25.945 , which falls below the 85th percentile on this growth chart. 


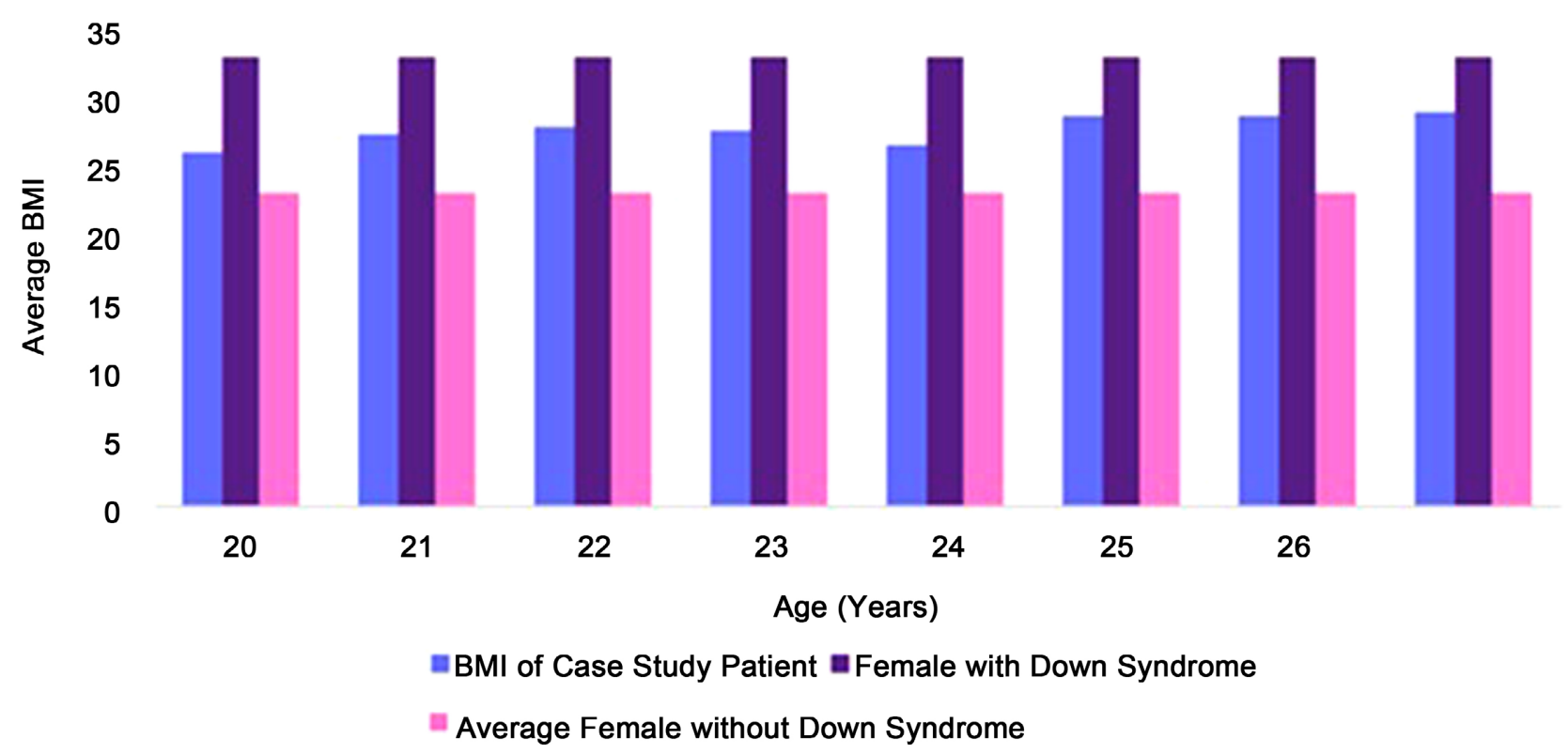

Figure 3. Average Body Mass Index (BMI) values of the case study patient through ages 20 - 27 (orchid) compared to the average BMI of a female with Down Syndrome age 20 - 27 (purple) and the average BMI of an average female without Down Syndrome age 20 - 27 (pink).

\section{Discussion}

Down Syndrome is associated with many health challenges including, but not limited to, physical facial abnormalities, cardiac defects, and developmental abnormalities. Notably, DS is associated with increased risk of overweight, obesity, metabolic syndrome, obstructive sleep apnea, thyroid disorders, autoimmune disease, hypotonia, and premature aging [13]. However, individuals with DS have the predisposition for altered body composition, overweight and obesity with early nutritional and lifestyle intervention; this does not need to be the case. Individuals with DS can develop healthy self-help behaviors given appropriate nurturing and tools [28] [29]. Diet intervention needs to minimize food jags and cue healthy food choices. Individuals with DS will accept less preferred foods or new foods, if given structured choices such as: "Would you like an apple or an orange?" versus "What do you want to eat?" Another concern common in the population affected with Down Syndrome is feeding problems which are developed from hypotonia and/or poor oral coordination that persist throughout the life span. These challenges not only impact feeding but can also contribute to other health issues such as constipation or risk of aspiration.

Given the complexity of obesity, what is the best diet pattern to recommend for individuals with Down Syndrome who potentially face health challenges unique to their diagnoses? Considering the complexities of both we implemented a calorie controlled, structured, high fiber, moderate fat, high protein, and low glycemic load meal plan for this patient. The Medical Nutrition Therapy (MNT) plan was: $\sim 35 \%$ heart healthy fat, $1.3 \mathrm{gm}$ protein $/ \mathrm{kg}$, low glycemic load diet with 30 grams of carbohydrates per meal and 15 grams per snack, with pro- 
tein spread throughout the meal plan to provide nutritional need and increase satiety [22] [29] [30]. The C-ICAN diet provides foods rich in monounsaturated fatty acids, which reduces systemic chronic inflammation [29].

Patients with intellectual disabilities are more likely to have poor quality diets compared to the general population. Individuals with DS frequently lack independence in the selection and preparation of their food choices, with a large role played by caregivers [30]. The C-ICAN meal patterning provides both the structure and guidance, which helped with patient acceptance of the meal plan. This enabled the caregivers to effectively implement the nutrition treatment plan. The structure of this diet plan could easily be followed even when multiple caregivers were involved in patient care if all caregivers involved understood the patient's nutrition plan. The frequency and composition of meals in the structure of this diet plan helped to decrease hunger felt by the patient, improve dietary satisfaction, and discourage her from sneaking food.

This retrospective case study is limited in that it is restricted to one patient's case, however, given the promising findings in this report there is an obvious need for further research involving anti-inflammatory nutrition interventions paired with a structured behavior plan as part of the overall goal of preventing obesity and associated co-morbidities in individuals with Down Syndrome.

\section{Conflicts of Interest}

The authors declare no conflicts of interest regarding the publication of this paper.

\section{References}

[1] Malt, E.A., Dahl, R.C., Haugsand, T.M., et al. (2013) Health and Disease in Adults with Down Syndrome. Tidsskrift for den Norske laegeforening. Tidsskrift for praktisk medicin, ny raekke, 133, 290-294. https://doi.org/10.4045/tidsskr.12.0390

[2] Prasher, V.P. (1995) Overweight and Obesity amongst Down's Syndrome Adults. Journal of Intellectual Disability Research, 39, 437-441. https://doi.org/10.1111/j.1365-2788.1995.tb00548.x

[3] Hill, D.L., Parks, E.P., Zemel, B.S., Shults, J., Stallings, V.A. and Stettler, N. (2013) Resting Energy Expenditure and Adiposity Accretion among Children with Down Syndrome: A 3-Year Prospective Study. European Journal of Clinical Nutrition, 67, 1087-1091. https://doi.org/10.1038/ejcn.2013.137

[4] Bertapelli, F., Pitetti, K., Agiovlasitis, S. and Guerra-Junior, G. (2016) Overweight and Obesity in Children and Adolescents with Down Syndrome-Prevalence, Determinants, Consequences, and Interventions: A Literature Review. Research in Developmental Disabilities, 57, 181-192. https://doi.org/10.1016/j.ridd.2016.06.018

[5] Tsou, A.Y., Bulova, P., Capone, G., et al. (2020) Medical Care of Adults with Down Syndrome: A Clinical Guideline. JAMA, 324, 1543-1556.

https://doi.org/10.1001/jama.2020.17024

[6] Chicoine, B., Rivelli, A., Fitzpatrick, V., Chicoine, L., Jia, G. and Rzhetsky, A. (2021) Prevalence of Common Disease Conditions in a Large Cohort of Individuals with Down Syndrome in the United States. Journal of Patient-Centered Research and Reviews, 8, 86-97. https://doi.org/10.17294/2330-0698.1824 
[7] Haslam, D.W. and James, W.P. (2005) Obesity. The Lancet, 366, 1197-1209. https://doi.org/10.1016/S0140-6736(05)67483-1

[8] Tomiyama, A.J., Hunger, J.M., Nguyen-Cuu, J. and Wells, C. (2016) Misclassification of Cardiometabolic Health When Using Body Mass Index Categories in NHANES 2005-2012. International Journal of Obesity, 40, 883-886. https://doi.org/10.1038/ijo.2016.17

[9] Ogden, C., Carroll, M., Fryar, C. and Flegal, K.M. (2015) Prevalence of Obesity among Adults and Youth: United States, 2011-2014 NCHS. NCHS Data Brief, No. 219, 1-8.

[10] Murray, C.J. (2018) The State of Us Health, 1990-2016: Burden of Diseases, Injuries, and Risk Factors among US States. JAMA, 319, 1444-1472.

https://doi.org/10.1001/jama.2018.0158

[11] Must, A., Curtin, C., Hubbard, K., Sikich, L., Bedford, J. and Bandini, L. (2014) Obesity Prevention for Children with Developmental Disabilities. Current Obesity Reports, 3, 156-170. https://doi.org/10.1007/s13679-014-0098-7

[12] Mazurek, D. and Wyka, J. (2015) Down Syndrome-Genetic and Nutritional Aspects of Accompanying Disorders. Roczniki Panstwowego Zakladu Higieny, 66, 189-194.

[13] Skinner, A.C. and Skelton, J.A. (2014) Prevalence and Trends in Obesity and Severe Obesity among Children in the United States, 1999-2012. JAMA Pediatrics, 168, 561-566. https://doi.org/10.1001/jamapediatrics.2014.21

[14] Ptomey, L.T., Saunders, R.R., Saunders, M., et al. (2018) Weight Management in Adults with Intellectual and Developmental Disabilities: A Randomized Controlled Trial of Two Dietary Approaches. Journal of Applied Research in Intellectual Disabilities, 31, 82-96. https://doi.org/10.1111/jar.12348

[15] Maki, K.C., Phillips-Eakley, A.K. and Smith, K.N. (2016) The Effects of Breakfast Consumption and Composition on Metabolic Wellness with a Focus on Carbohydrate Metabolism. Advances in Nutrition (Bethesda, Md.), 7, 613s-621s. https://doi.org/10.3945/an.115.010314

[16] Singh, N.N., Fau, L.G., Fau, S.A., et al. (2008) A Mindfulness-Based Health Wellness Program for an Adolescent with Prader-Willi Syndrome. Behavior Modification, 32, 167-181. https://doi.org/10.1177/0145445507308582

[17] Izquierdo-Gomez, R., Martinez-Gomez, D., Fernhall, B., Sanz, A. and Veiga, O.L. (2005) The Role of Fatness on Physical Fitness in Adolescents with and without Down Syndrome: The UP \& DOWN Study. International Journal of Obesity, 40, 22-27. https://doi.org/10.1038/ijo.2015.164

[18] Zhu, Y. and Hollis, J.H. (2016) Associations between Eating Frequency and Energy Intake, Energy Density, Diet Quality and Body Weight Status in Adults from the USA. The Journal of Nutrition, 115, 2138-2144. https://doi.org/10.1017/S0007114516001112

[19] Schmidt, J.B., Gregersen, N.T., Pedersen, S.D., et al. (2014) Effects of PYY3-36 and GLP-1 on Energy Intake, Energy Expenditure, and Appetite in Overweight Men. American Journal of Physiology. Endocrinology and Metabolism, 306, E1248-E1256. https://doi.org/10.1152/ajpendo.00569.2013

[20] Kraschnewski, J.L., Boan, J., Esposito, J., et al. (2005) Long-Term Weight Loss Maintenance in the United States. International Journal of Obesity, 34, 1644-1654. https://doi.org/10.1038/ijo.2010.94

[21] Bertapelli, F., Machado, M.R., Roso, R.D. and Guerra-Junior, G. (2017) Body Mass Index Reference Charts for Individuals with Down Syndrome Aged 2-18 Years. 
Jornal de Pediatria, 93, 94-99. https://doi.org/10.1016/j.jped.2016.04.005

[22] Slagter, S.N., Corpeleijn, E., van der Klauw, M.M., et al. (2018) Dietary Patterns and Physical Activity in the Metabolically (Un)healthy Obese: The Dutch Lifelines Cohort Study. Nutrition Journal, 17, 18. https://doi.org/10.1186/s12937-018-0319-0

[23] Ebbeling, C.B., Swain, J.F., Feldman, H.A., Wong, W., Hachey, D., Garcia-Lago, E. and Ludwig, D.S. (2012) Effects of Dietary Composition on Energy Expenditure during Weight-Loss Maintenance. JAMA, 307, 2627-2634. https://doi.org/10.1001/jama.2012.6607

[24] Becker, G.F., Passos, E.P. and Moulin, C.C. (2015) Short-Term Effects of a Hypocaloric Diet with Low Glycemic Index and Low Glycemic Load on Body Adiposity, Metabolic Variables, Ghrelin, Leptin, and Pregnancy Rate in Overweight and Obese Infertile Women: A Randomized Controlled Trial. The American Journal of Clinical Nutrition, 102, 1365-1372. https://doi.org/10.3945/ajcn.115.117200

[25] Grammatikopoulou, M.G., Manai, A.F., Tsigga, M.F., Tsiligiroglou-Fachantidou, A.F., Galli-Tsinopoulou, A.F. and Zakas, A. (2008) Nutrient Intake and Anthropometry in Children and Adolescents with Down Syndrome-A Preliminary Study. Developmental Neurorehabilitation, 11, 260-267.

https://doi.org/10.1080/17518420802525526

[26] Weems, M., Truex, L., Scampini, R., Fleming, R., Curtin, C. and Bandini, L. (2017) A Novel Weight-Loss Tool Designed for Adolescents with Intellectual Disabilities. Journal of the Academy of Nutrition and Dietetics, 117, 1503-1508. https://doi.org/10.1016/j.jand.2016.09.006

[27] Pedrollo, E.F., Nicoletto, B.B., Carpes, L.S., et al. (2017) Effect of an Intensive Nutrition Intervention of a High Protein and Low Glycemic-Index Diet on Weight of Kidney Transplant Recipients: Study Protocol for a Randomized Clinical Trial. Trials, 18, 413. https://doi.org/10.1186/s13063-017-2158-2

[28] Maki, K.C., Eren, F., Cassens, M.E., Dicklin, M.R. and Davidson, M.H. (2018) $\Omega-6$ Polyunsaturated Fatty Acids and Cardiometabolic Health: Current Evidence, Controversies, and Research Gaps. Advances in Nutrition, 9, 688-700. https://doi.org/10.1093/advances/nmy038

[29] Juanola-Falgarona, M., Salas-Salvado, J., Ibarrola-Jurado, N., et al. (2014) Effect of the Glycemic Index of the Diet on Weight Loss, Modulation of Satiety, Inflammation, and Other Metabolic Risk Factors: A Randomized Controlled Trial. The American Journal of Clinical Nutrition, 100, 27-35.

[30] Hoey, E., Staines, A., Walsh, D., et al. (2017) An Examination of the Nutritional Intake and Anthropometric Status of Individuals with Intellectual Disabilities: Results from the SOPHIE Study. Journal of Intellectual Disabilities, 21, 346-365.

https://doi.org/10.1177/1744629516657946 